ORIGINAL RESEARCH

\title{
Orofacial Cancer Situation of Lithuanian Population in the Period of 2010-2016
}

\author{
Gabrielè Šulcaitè ${ }^{1}$, Laura Jacinkevičiūtè ${ }^{2}$, Dominyka Grinkevičiené ${ }^{3}$, Gediminas Skirbutis ${ }^{4}$
}

\begin{abstract}
Relevance of the problem and aim and objective: Massive bone and soft tissue defects are seen after oncological maxillofacial operations. Surgeons and prosthodontists must cooperate and make a basic treatment plan. It is essential to improve the quality of life of the patient after completely removing the tumor, restoring masticatory function, and improving esthetic appearance. The study aims to collect and analyze the data of patients with orofacial malignant tumors during the period from 2010 to 2016 in the Hospital of Lithuanian University of Health Sciences (HLUHS) Department of Otorhinolaryngology and Department of Maxillofacial Surgery, National Cancer Institute (NCI) Department of Head and Neck Surgery, Klaipeda University Hospital and find out the availability and their need for rehabilitation and prosthetic treatment. Materials and methods: Patient disease data analysis was performed using the International classification of diseases (ICD) according to malignant tumors localization of the maxillofacial region. The medical records were arranged by age, sex, origin, profession, tumor localization, stage, type, treatment, and prosthetic needs for the patient. Data analysis was carried out using IBM SPSS 25 and Microsoft Excel 2016 software packages. Results: The study involved 827 men and 699 women, the mean age was 68 years. Defects of the lower jaw were detected in 87 patients, of the ear- 52 cases in the whole sample. $11.34 \%$ of patients required prosthetics to restore the defects after resection.

Conclusion: Among 1,526 analyzed cases, prosthetic treatment of the facial defects is required in $11.34 \%$ of patients.

Keywords: Maxillofacial surgery, Orofacial cancer, Rehabilitation.

Journal of Contemporary Dentistry (2020): 10.5005/jp-journals-10031-1273
\end{abstract}

\section{INTRODUCTION}

Cancer is the most severe issue in our society. According to the data provided by The National Cancer Institute $(\mathrm{NCl})$, the number of patients continues to grow. Orofacial cancer is one of the most commonly diagnosed oncological diseases in the facial and neck areas. It reaches around 263,000 cases every year worldwide. ${ }^{1}$ In Lithuania, a statistical overview of patients with facial oncological diseases has not been performed since 2000, when it was done by Doctor Tomas Linkevicius, together with the co-authors. ${ }^{2}$

The most common cause of malign oral cancer is squamous cell carcinoma. ${ }^{3}$ Oncological damage spreads around the oral cavity: Periodontal tissue, tongue, parotid, submandibular and sublingual salivary glands, lower and upper jaws, temporal bone, muscles of the lower jaw, nose, ears, and facial skin. ${ }^{4}$ The leading causes of orofacial oncological diseases are poor oral hygiene, chronic periodontal diseases, and human papillomavirus. The crucial impact on the illness is also caused by predisposing factors: Constant stress, smoking, or heavy use of medications. ${ }^{3,5}$

Patients with oncological diseases regularly face many psychological and physical issues. The main problems after surgeries and radiation therapy in orofacial areas include longlasting postoperative pain, disturbed chewing, swallowing, and lingual functions. Postoperative defects of massive bone and soft tissues cause significant facial esthetic infringements, which are essential for the latter patient adaptation in society. ${ }^{1,4,6}$ Due to the mentioned reasons, the tasks of oral and maxillofacial surgeons and dentists-orthopedists are to completely remove the tumor and attempt to recreate the impacted functions after the surgery and improving the patient esthetics as well as the quality of life.

Objective to perform an analysis of patients with orofacial malignant tumors during the period between 2010 and 2016 in
${ }^{1-4}$ Department of Prosthodontics, Lithuanian University of Health Sciences, Kaunas, Kauno Apskritis, Lithuania

Corresponding Author: Gabrielè Šulcaitè, Department of Prosthodontics, Lithuanian University of Health Sciences, Kaunas, Kauno Apskritis, Lithuania, Phone: +37069976877, e-mail: gabrielesulcaite@gmail.com

How to cite this article: Šulcaitè G, Jacinkevičiūtė L, Grinkevičienè D, et al. Orofacial Cancer Situation of Lithuanian Population in the Period of 2010-2016. J Contemp Dent 2020;10(1):30-33.

Source of support: Nil

Conflict of interest: None

the HLUHS Departments of Otorhinolaryngology and Maxillofacial Surgery, Klaipeda University Hospital, NCI Department of Head and Neck Surgery, and find out their need for rehabilitation and prosthetic treatment.

\section{Materials and Methods}

The research was performed at the HLUHS Departments of Otorhinolaryngology and Maxillofacial Surgery, Klaipeda University Hospital, NCl Department of Head and Neck Surgery, during the period from 2010 to 2016. After submitting all the required approvals, the authorization (No. BEC-LSMU(R)-34) was issued by The Centre of Bioethics at The Lithuanian University of Health Sciences.

Confidentiality of the subjects was ensured according to The Provisions of the Patient Rights and Health Compensation Act; the name, surname, address, and other personal details of the patients were not collected. 
Medical records were analyzed according to these criteria: Years, department, gender, the area of impact, defect restoration, further treatment, and prosthetic treatment. The data were entered into a Microsoft Excel 2016 spreadsheet.

Statistical analysis was performed using IBM SPSS Statistics 25 and Microsoft Excel 2016 software.

\section{Results}

\section{General Information about the Subjects}

While performing the research, 1,526 medical records of the patients with orofacial oncological cancer were chosen. Two hundred and seventeen patients were treated at the Department of Maxillofacial Surgeries and 53 patients at the Department of Otorhinolaryngology, 123 were at the Klaipeda University Hospital, and 1,133 were at the $\mathrm{NCl}$ Department of Head and Neck Surgery.

The study involved 827 men and 699 women. The age of the patients spanned from 12 to 98 years. The mean age of the participants was 68 years.

\section{Localization of Lesions and Applied Treatment Methods}

The majority of the patients who required orofacial prosthetic treatment were observed at the HLUHS (23.3\%): The mandible defects were diagnosed to 64 patients, the floor of the mouth55 , tongue -36 cases in the sample. The general localization distribution is displayed in Figure 1.

In $58.4 \%$ of the cases at the HLUHS during the surgical operations, the excision was performed for the damaged tissue, the resection of the damaged organ was performed in $5.9 \%$ of the cases. Figure 2 displays the frequency of treatment methods for inpatient patients.

The graph displayed in Figure 3 shows what treatment methods were chosen at the HLUHS with different localizations on the defects.

In most cases, at the HLUHS (75\%) after the surgical operation, the defects were seen, reconstructive surgeries were applied to $6 \%$ of the cases.

The majority of the inpatients at the HLUHS (74.07\%) have been recommended to come in for a consultation and control studies, $20 \%$ have been prescribed with radiation treatment, medicinal treatment was prescribed to $5.93 \%$ of the patients.

After analyzing the data from all of the clinics, $11.34 \%$ (173 patients) with orofacial malignant tumors required prosthetic treatment to restore the defects (Table 1). The diagram displayed in Figure 4 shows how the need for prosthetic treatment is distributed by the localization of the defect.

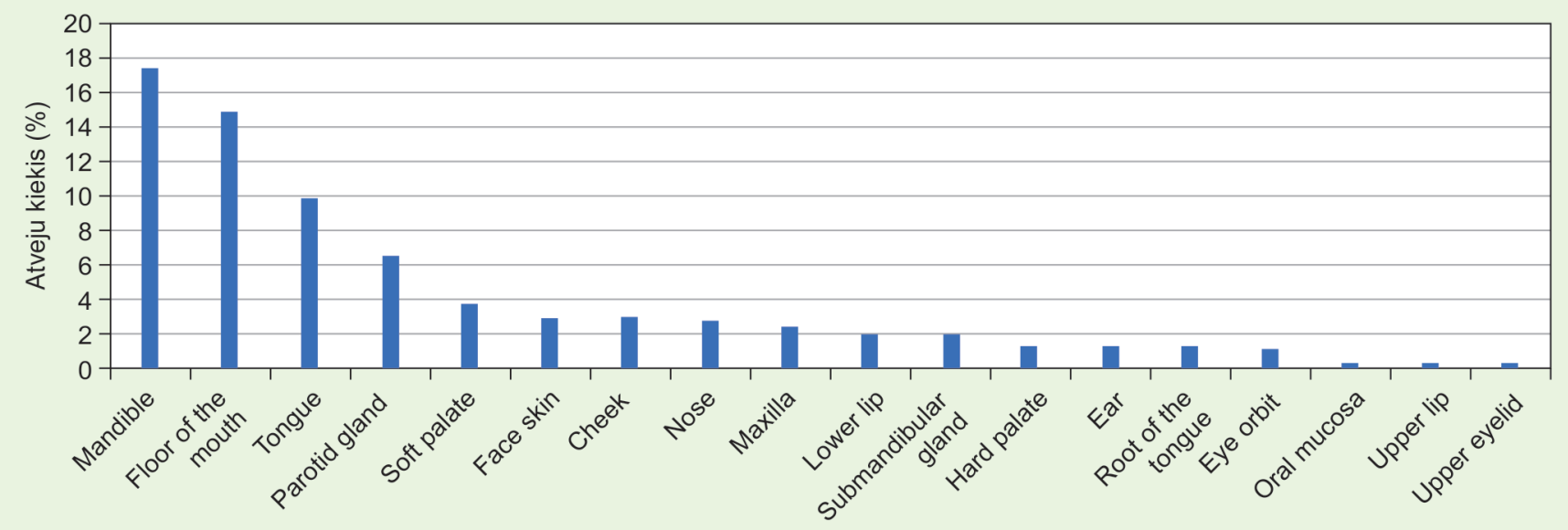

Fig. 1: Distribution of localization of lesions

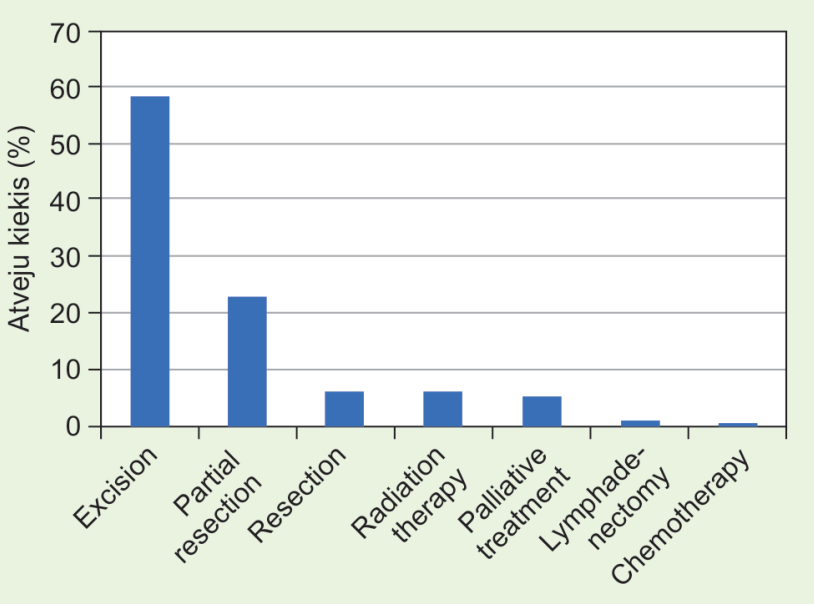

Fig. 2: Patients treatment methods

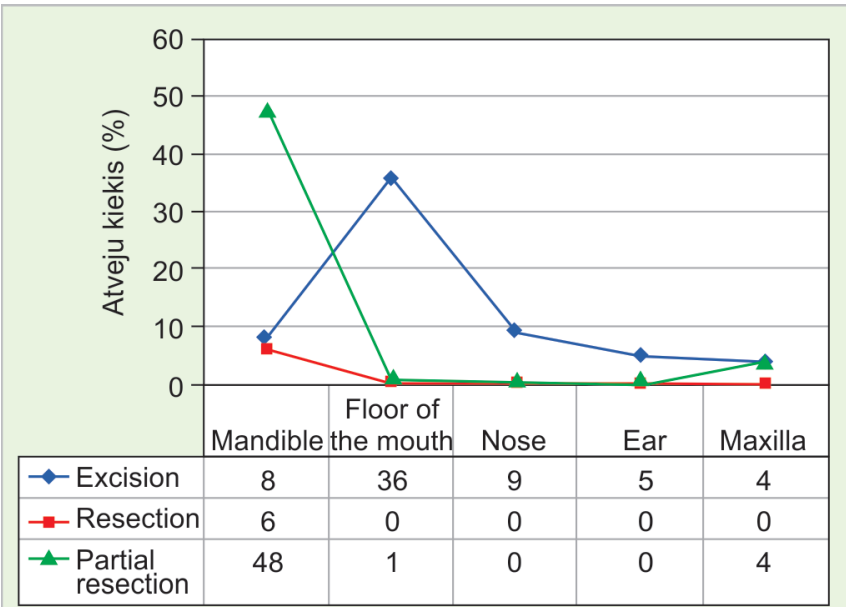

Fig. 3: Localization of lesions and treatment method distribution 
Table 1: Prevalence and need for prosthetic rehabilitation of orofacial cancer

\begin{tabular}{lcc}
\hline & $\begin{array}{l}\text { Patients, who have } \\
\text { suffered orofacial } \\
\text { resection }\end{array}$ & $\begin{array}{l}\text { Patients, who } \\
\text { need prosthetic } \\
\text { rehabilitation }\end{array}$ \\
\hline $\begin{array}{l}\text { Klaipeda University Hospital } \\
\text { Hospital of Lithuanian }\end{array}$ & 65 & $6(9.2 \%)$ \\
$\begin{array}{l}\text { University of Health } \\
\text { Sciences Department of } \\
\text { Otorhinolaryngology and } \\
\text { Department of Maxillofacial } \\
\text { Surgery }\end{array}$ & 159 & $38(23.9 \%)$ \\
$\begin{array}{l}\text { National Cancer Institute } \\
\text { Department of Head and Neck } \\
\text { Surgery }\end{array}$ & 567 & \\
Total & 791 & $45(7.9 \%)$ \\
\hline
\end{tabular}

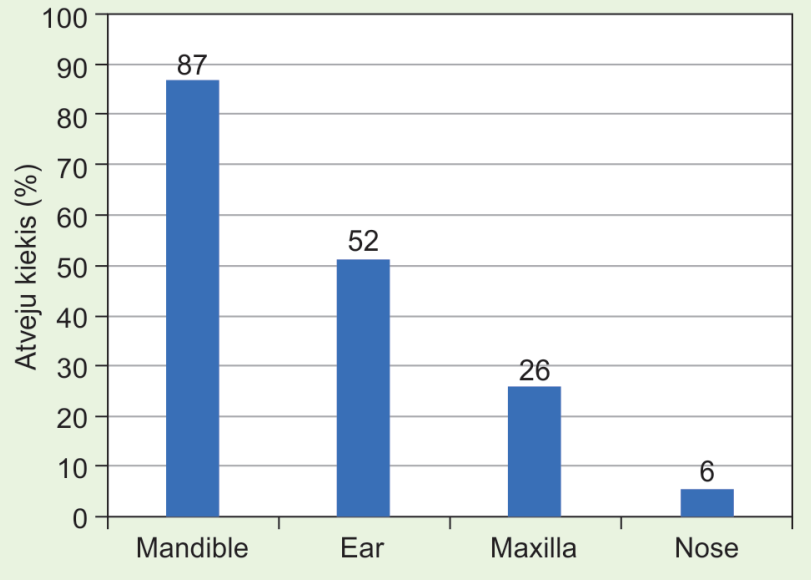

Fig. 4: Prosthetics of postsurgical defects

\section{Discussion}

During the research, the medical records of the patients with orofacial malignant tumors from 2010 to 2016 were analyzed. After evaluating the results, we can observe the largest percentage of the patients who required orofacial prosthetic treatment was at the HLUHS (23.3\%).

The majority of the patients were men (54.2\%). The more common morbidity of orofacial oncological diseases of men is also shown by Beck-Broichsitter et al. performed a study about the rehabilitation of orofacial oncological patients ${ }^{7}$ and the study by Farhangfar et al. and other Canadian scientists, where they have covered the symptoms faced by the oncological patients. ${ }^{8}$

The mean age of the study participants (male and female) was 68 years. The same mean age was in the study by Farhangfar et al. ${ }^{8}$ In the study executed by Mercadante et al., the mean age was larger by 10 years; ${ }^{9}$ however, the results of all three studies show that oncological orofacial diseases are usually diagnosed for elder people.

After assessing the distribution of damage localization, it is clear that the most common diagnosis is for tumors in the lower jaw, the floor of the mouth, tongue, and parotid glands. The results of studies by Farhangfar et al. and Beck-Broichsitter et al. also show similar localization distribution and further supplement the results of our study - that oncological illnesses most commonly are displayed on the tongue, the parotid glands, and the floor of the mouth. ${ }^{7,8}$ The study by Farhangfar et al. states that $1.4 \%$ of the tumors were diagnosed in the nasal cavity and middle years, also similar distribution was noticed while analyzing the results of our research - nasal tumors were diagnosed for $2.7 \%$ of all patients, while ear- $1.4 \% .^{8}$

Surgical treatment was applied to $87.3 \%$ of all patients, $6 \%$ of which received a reconstructive defect restoration with a plate or transplant. While in the study by Beck-Broichsitter et al., reconstructive surgical treatment was performed in one-third of all the cases. ${ }^{7}$

$11.34 \%$ of all the patients with orofacial malignant oncological diseases required prosthetic postoperative treatment to restore defects, of which $87 \%$ of cases analyzed in the research were to restore the lower jawbone. It is a significant percentage; thus, it is essential that even before the surgery, the further treatment plan is covered and the prosthetic treatment opportunities would be covered. ${ }^{10,11}$

\section{ConCLUSION}

One thousand five hundred and twenty-six cases were analyzed during the period from 2010 to 2016 in the HLUHS Departments of Otorhinolaryngology and Maxillofacial Surgery, Klaipeda University Hospital, and NCI Department of Head and Neck Surgery. Surgical treatment was performed for $87.3 \%$ cases of the Hospital of Lithuanian University of Health Sciences, for the remaining part of patients (12.6\%) were given non-radical treatment methods. $11.34 \%$ with orofacial malignant tumors required prosthetic treatment to restore the defects.

\section{References}

1. Barrios R, Tsakos G, García-Medina B, et al. Oral health-related quality of life and malnutrition in patients treated for oral cancer. Support Care Cancer 2014;22(11):2927-2933. DOI: 10.1007/s00520-014-2281-5.

2. Reitemeier B, Schöne C, Schreiber S, et al. Planning implant positions for an auricular prosthesis with digital data. J Prosthet Dent 2012;107(2):128-131. DOI: 10.1016/S0022-3913(12)60038-9.

3. Karbach J, Al-nawas B, Moergel M, et al. Oral health-related quality of life of patients with oral lichen planus, oral leukoplakia, or oral squamous cell carcinoma. J Oral Maxillofac Surg 2014;72(8):1517-1522. DOI: 10.1016/j.joms.2014.04.008.

4. Stuani VT, Santos PSS, Damante CA, et al. Oral health impact profile of head and neck cancer patients after or before oncologic treatment: an observational analytic case-control study. Support Care Cancer 2018;26(7):2185-2189. DOI: 10.1007/s00520-018-4066-8.

5. Bertl K, Loidl S, Kotowski U, et al. Oral health status and dental care behaviours of head and neck cancer patients: a cross-sectional study in an Austrian tertiary hospital. Clin Oral Investig 2016;20(6):1317-1327. DOI: 10.1007/s00784-015-1618-x.

6. Mücke T, Koschinski J, Wolff KD, et al. Quality of life after different oncologic interventions in head and neck cancer patients. J Craniomaxillofac Surg 2015;43(9):1895-1898. DOI: 10.1016/ j.jcms.2015.08.005.

7. Beck-Broichsitter BE, Huck J, Küchler T, et al. Self-perception versus professional assessment of functional outcome after ablative surgery in patients with oral cancer. J Cancer Res Clin Oncol 2017;143(2): 305-311. DOI: 10.1007/s00432-016-2287-0HYPERLINK “https://link. springer.com/journal/432" \o "Journal of Cancer Research and Clinical Oncology".

8. Farhangfar A, Makarewicz M, Ghosh S, et al. Nutrition impact symptoms in a population cohort of head and neck cancer patients: 
Multivariate regression analysis of symptoms on oral intake, weight loss and survival. Oral Oncol 2014;50(9):877-883. DOI: 10.1016/ j.oraloncology.2014.06.009.

9. Mercadante S, Aielli F, Adile C, et al. Prevalence of oral mucositis, dry mouth, and dysphagia in advanced cancer patients. Support Care Cancer 2015;23(11):3249-3255. DOI: 10.1007/s00520-015-2720-y.

10. Dholam KP, Dugad JA, Sadashiva KM. Impact of oral rehabilitation on patients with head and neck cancer: a study using the liverpool oral rehabilitation questionnaire and the oral health impact Profile-14. J Prosthet Dent 2017;117(4):559-562. DOI: 10.1016/ j.prosdent.2016.06.019.

11. Huber GF, Dort JC. Reducing morbidity and complications after major head and neck cancer surgery: the (future) role of enhanced recovery after surgery protocols. Curr Opin Otolaryngol Head Neck Surg 2018;26(2):71-77. DOI: 10.1097/MOO.000000 0000000442. 